\title{
Faktor yang Mempengaruhi Partisipasi Petani dalam Kegiatan Pengolahan Pupuk Organik di Desa Banjaratma, Kecamatan Bulakamba, Kabupaten Brebes
}

Nisita Wuri $^{1 *}$, Sugihardjo ${ }^{1}$, Agung Wibowo ${ }^{1}$

${ }^{1}$ Program Studi Penyuluhan dan Komunikasi Pertanian, Fakultas Pertanian Universitas Sebelas Maret Surakarta

\begin{tabular}{l}
\hline \multicolumn{1}{c}{ ARTIKEL INFO } \\
\hline Sejarah artikel \\
Diterima 30/04/2021 \\
Diterima dalam bentuk revisi 03/06/2021 \\
Diterima dan disetujui 07/06/2021 \\
Tersedia online 22/06/2021 \\
\hline Kata kunci \\
Kelompok tani \\
Partisipasi \\
Petani \\
Pupuk Organik \\
\hline
\end{tabular}

\begin{abstract}
ABSTRAK
Kegiatan pengolahan pupuk organik merupakan kegiatan kelompok yang dilakukan oleh Kelompok Tani Bahagia IV. Kegiatan ini didorong oleh keprihatinan petani terhadap semakin menurunnya kesuburan lahan sebagai dampak negatif penggunaan pupuk kimia selama puluhan tahun. Sebagai kegiatan kelompok, tentu membutuhkan partisipasi petani untuk menjaga keberlanjutan kegiatan. Penelitian bertujuan untuk mengetahui berbagai faktor yang mempengaruhi partisipasi petani dalam kegiatan pengolahan pupuk organik di Kelompok Tani Bahagia IV. Metode penelitian yang digunakan yaitu deskriptif kualitatif. Lokasi penelitian dipilih secara sengaja yaitu kelompok tani Bahagia IV yang berada di Desa Banjaratma, Kecamatan Bulakamba, Kabupaten Brebes dengan pertimbangan kelompok tersebut secara konsisten memproduksi pupuk organik untuk memenuhi kebutuhan petani. Informan penelitian meliputi Ketua Kelompok Tani Bahagia IV, Dinas Pertanian dan Ketahanan Pangan Kabupaten Brebes, Kepala BPP Kecamatan Bulakamba, pengurus kegiatan pengolahan pupuk organik serta petani anggota kelompok. Data penelitian diperoleh dengan teknik observasi, wawancara mendalam, serta dokumentasi. Analisis data menggunakan model analisis Interaktif, serta validitas data menggunakan triangulasi sumber. Hasil penelitian menunjukkan faktor yang mempengaruhi partisipasi petani dalam kegiatan pengolahan pupuk organik meliputi umur, pendidikan formal dan atau nonformal petani, pekerjaan serta akses komunikasi. Salah satu upaya untuk meningkatkan partisipasi petani yaitu dengan membuat jadwal bagi petani dalam proses produksi, sehingga setiap individu petani memiliki peran dan tanggung jawab yang sama atas keberlangsungan kegiatan. Optimalisasi peran serta petani dalam pengolahan pupuk organik sebagai kegiatan usaha kelompok perlu direalisasikan, agar dapat berkembang menjadi usaha kelompok yang lebih baik.
\end{abstract}




\section{ABSTRACT}

Organic fertilizer processing is a group activity carried out by Bahagia IV farmers group, because of concerned about the decline in land fertility as a result of the negative impact of using chemical fertilizers for decades. As a group activity, it certainly requires the participation of farmers. This study aims to determine factors that influencing farmers to participate in organic fertilizer processing's group activities. The basic method research is descriptive research method with a qualitative approach. The research location in Bahagia IV farmers' group, Banjaratma Village, Bulakamba District, Brebes Regency with the consideration that the group consistently produces organic fertilizers to meet farmers' needs. The research informants included the Head of Bahagia $I V$ farmers' group, the Office of Agriculture and Food Security of Brebes Regency, the Head of BPP

\section{PENDAHULUAN}

Lahan yaitu tanah beserta faktor-faktor fisik lingkungannya seperti lereng, hidrologi, iklim dan lainnya, yang secara potensial berpengaruh terhadap penggunaan lahan (Hardjowigeno, 2007). Lahan akan memberikan manfaat utamanya dalam produksi pertanian apabila petani mengelola secara tepat dan sebaliknya, lahan yang dimanfaatkan secara tidak tepat dapat mengakibatkan kerusakan ekosistem serta penurunan produktivitas. Setyorini mengungkapkan penurunan poduktivitas lahan dikarenakan adanya aktivitas pengelolaan lahan secara berlebihan (over exploitation). Defisit hara, pemupukan yang tidak berimbang, serta berkurangnya kadar bahan organik dalam tanah jturut mendukung terjadinya penurunan produktivitas lahan.

Di Indonesia sendiri, penurunan kualitas lahan sawah antara lain disebabkan sebagian besar pertanian yang mengembangkan sistem pertanian modern, dalam hal ini revolusi hijau. Pertanian modern yang ditunjukkan
Bulakamba District, the management of organic fertilizer processing activities and farmers group members. Research data obtained by observation techniques, in-depth interviews, and documentation. Data were analyzed using interactive analysis models, data validity using source triangulation. Factors that affecting farmers' participation including age, formal and non-formal education of farmers, employment and access to communicate. Efforts that can be made to increase farmer participation are by making a schedule for farmers in the production process, so that each individual farmer has the same role and responsibility for the sustainability of the activity. Optimizing the participation of farmers in organic fertilizer processing as a group business activity needs to be realized, so that it can develop into a better group business.

dengan pemupukan pestisida dosis tinggi, tidak hanya memacu pertumbuhan tanaman dan meningkatkan hasil pertanian, tetapi juga menyebabkan ketergantungan terhadap pupuk kimia.

Kelompok Tani Bahagia IV Desa Banjaratma, Kecamatan Bulakamba, Kabupaten Brebes dengan mayoritas sebagai petani komoditas bawang merah, merupakan salah satu kelompok tani yang menyadari dan merasakan dampak penggunaan pupuk kimia dalam jangka waktu lama terhadap lahan sawah mereka. Hasil observasi menunjukkan penggunaan pupuk kimia selama puluhan tahun oleh petani, menimbulkan tanah resisten terhadap pupuk kimia. Oleh karena itu petani menjadi ketergantungan dengan terus menggunakan pupuk kimia dalam usaha taninya.

Penelitian yang dilakukan Bahar (2016) mengungkapkan bahwa penggunaan bahan kimia oleh petani bawang merah di Kabupaten Brebes masih sangat intensif. Hal tersebut ditunjukkan dengan 
perilaku petani di lapang yang menggunakan pupuk kimia tidak sesuai yang dianjurkan, baik dari jumlah, jenis maupun cara penerapannya. Budidaya bawang merah secara intensif bukan hanya memberikan keuntungan secara ekonomi dan kesejahteraan petani, akan tetapi juga berdampak negatif terhadap lingkungan serta kondisi sumber daya lahan.

Salah satu cara yang disarankan dalam pemeliharaan sumber daya lahan oleh Suradisastra (2010) dan Sumarno (2012) yaitu dengan penggunaan pupuk berimbang, serta pengembangan dan atau penambahan pupuk organik secara teratur. Berkaitan dengan urgensi pemeliharaan sumber daya lahan melalui pengembangan serta penggunaan pupuk organik, Kelompok Tani Bahagia IV dari Desa Banjaratma, Kecamatan Bulakamba, Kabupaten Brebes melakukan kegiatan pengembangan usaha pengolahan pupuk organik. Kelompok Tani Bahagia IV merupakan kelompok tani di Kabupaten Brebes yang melakukan pengolahan pupuk organik sebagai kegiatan kelompok, dengan hasil produk yang dikomersialkan ke petani-petani. Pada pelaksanaannya, kegiatan pengolahan pupuk organik tentu membutuhkan partisipasi anggota, karena partisipasi petani dapat berpengaruh pada keberlangsungan dan atau keberlanjutan kegiatan. Penelitian ini bertujuan menganalisis secara deskriptif berbagai faktor yang mempengaruhi partisipasi petani dalam kegiatan pengolahan pupuk organik.

\section{METODE}

Penelitian ini menggunakan metode kualitatif deskriptif. Sugiyono (2009) menyebutkan metode kualitatif sebagai metode penelitian untuk mendapatkan data yang mendalam, data yang sebenarnya. Menurut Faisal (1992), pendekatan deskriptif kualitatif dalam penelitian bertujuan untuk mendeskripsikan secara rinci dan mendalam terkait perilaku orang, peristiwa lapangan, serta kegiatan tertentu.

Lokasi penelitian ditentukan secara sengaja (purposive) sesuai dengan tujuan penelitian, yaitu Kelompok Tani Bahagia IV di Desa Banjaratma, Kecamatan Bulakamba, Kabupaten Brebes dengan pertimbangan merupakan kelompok tani yang mengembangkan kegiatan usaha pengolahan pupuk organik sebagai kegiatan kelompok. Desa Banjaratma melalui Kelompok Tani Bahagia IV juga ditunjuk menjadi salah satu rintisan desa organik dalam program pengembangan 1000 desa organik oleh pemerintah pada tahun 2019 .

Informan penelitian meliputi Ketua Kelompok Tani Bahagia IV, Dinas Pertanian dan Ketahanan Pangan Kabupaten Brebes, Kepala BPP Kecamatan Bulakamba, pengurus kegiatan pengolahan pupuk organik serta petani anggota kelompok. Data dalam penelitian ini diperoleh dengan teknik observasi, wawancara mendalam (in-depth interview), serta dokumentasi. Analisis data menggunakan model analisis Interaktif, meliputi reduksi data, sajian data dan kesimpulan/verifikasi. Validitas data yang digunakan yakni triangulasi sumber. Moelong (2000) mengungkapkan triangulasi sebagai teknik pemeriksaan data dengan memanfaatkan sesuatu di luar data itu, yang 
dilakukan sebagai pembanding atau untuk mengecek keabsahan data tersebut.

\section{HASIL DAN PEMBAHASAN}

Kegiatan pengolahan pupuk organik merupakan kegiatan kelompok yang dilaksanakan secara mandiri oleh Kelompok Tani Bahagia IV, Desa Banjaratma, Kecamatan Bulakamba, Kabupaten Brebes. Kekhawatiran dan kesadaran akan penggunaan pupuk kimia berlebih yang mengakibatkan produktivitas lahan menurun, mendorong Ketua Kelompok Tani Bahagia IV, mengembangkan pupuk organik dengan memanfaatkan pengetahuan yang didapat dari berbagai pelatihan mengenai pupuk organik yang pernah diikuti.

Ketua dan anggota Kelompok Tani Bahagia IV pada tahun 2006 mengembangkan pupuk organik dengan melakukan produksi yang hasilnya dimanfaatkan oleh petani Kelompok Tani Bahagia IV. Pada tahun 2008 dengan bimbingan serta pembinaan dari dinas pertanian dan ketahanan pangan Kabupaten Brebes, produk pupuk kompos mulai diproduksi massal untuk petani konsumen di luar kelompok. Selanjutnya di tahun 2012, Kelompok Tani Bahagia IV mendapatkan bantuan dari dinas pertanian berupa fasilitas UPPO (Unit Pengolahan Pupuk Organik) yang diwujudkan dalam bentuk rumah kompos, mesin perajang kompos, kandang sapi dan sapi sebanyak 14 ekor. Sampai sekarang, pupuk kompos yang dihasilkan per bulannya kurang lebih mencapai 15 ton kompos yang diproduksi untuk memenuhi kebutuhan petani baik petani di sekitar Kecamatan Bulakamba maupun petani di lingkup Kabupaten Brebes.
Sebagai kegiatan kelompok,

pengolahan pupuk organik dapat berjalan karena adanya partisipasi dari petani yang tergabung dalam Kelompok Tani Bahagia IV. Mardikanto (2013) mendefinisikan partisipasi sebagai bentuk keterlibatan seseorang secara aktif dan sukarela, baik karena alasan-alasan dari dalam (intrinsik) maupun dari luar (ekstrinsik) dalam keseluruhan proses kegiatan. Berikut ini adalah faktor-faktor yang mempengaruhi partisipasi petani Kelompok Tani Bahagia IV dalam kegiatan pengolahan pupuk organik:

\section{Umur}

Umur petani merupakan lama waktu hidup petani. Tjiptoherijanto dalam Bappenas (2001) menyatakan bahwa di dalam analisis demografi, struktur umur penduduk dibedakan menjadi tiga kelompok, yaitu kelompok umur muda, di bawah 15 tahun; kelompok umur produktif, usia 15 - 64 tahun; dan kelompok umur tua, usia 65 tahun ke atas. Berdasarkan penelitian lapang, sebagian besar petani Kelompok Tani Bahagia IV yang ikut serta dalam kegiatan pengolahan pupuk organik berada pada umur antara $30-60$ tahun dan merupakan petani usia produktif, artinya kegiatan pengolahan pupuk organik bisa dilaksanakan dengan optimal, memanfaatkan tenaga fisik yang tersedia.

Kegiatan pengolahan pupuk organik sebagai usaha kelompok bertujuan untuk mendapat keuntungan (komersialisasi). Keuntungan tersebut dapat terwujud apabila kelompok tani mampu memenuhi pesanan konsumen dengan 
memanfaatkan tenaga dan waktu untuk produksi secara efektif dan efisien. Petani yang mengikuti kegiatan pengolahan pupuk organik, berada pada kisaran umur $30-60$ tahunan, yang termasuk usia produktif, memiliki tenaga fisik dan stamina yang bagus dibandingkan dengan petani usia tua. Tenaga fisik dan stamina petani usia produktif yang optimal menyebabkan kegiatan produksi pupuk organik dapat berjalan optimal dan menguntungkan kelompok. Sementara itu, petani dengan umur tua menghabiskan seluruh tenaganya di sawah sehingga sulit bagi mereka untuk ikut serta dalam kegiatan kelompok, seperti kegiatan pengolahan pupuk organik.

Soekarwati (2005) menyebutkan bahwa dibandingkan petani muda, petani yang lebih tua kurang dapat menerima perubahan. Hal tersebut dikarenakan berbagai faktor, seperti kesehatan, kekuatan atau stamina yang menurun serta keinginan petani untuk menikmati masa tua, menghambat petani untuk dapat dimaksimumkan pendapatannya. Penelitian Pan (2014) menunjukkan bahwa petani tua kurang suka untuk berpartisipasi dalam kegiatan program penyuluhan pertanian. Sementara Yanto et al. (2003) menyatakan petani umur muda dan dewasa berada pada kondisi ideal untuk melakukan perubahan dalam kegiatan pertanian, dikarenakan petani usia muda masih memiliki harapan terkait kegiatan usahataninya.

\section{Pendidikan}

Pendidikan dalam Undang-Undang Republik Indonesia (UU RI) No. 20 tahun 2003 disebutkan sebagai usaha sadar dan terencana untuk mewujudkan suasana belajar dan proses pembelajaran agar peserta didik secara aktif mengembangkan potensi dirinya. Jalur pendidikan terdiri atas pendidikan formal, nonformal dan informal yang dapat saling melengkapi dan memperkaya.

a. Pendidikan Formal

Pendidikan merupakan indikator sumber daya manusia yang umumnya mendorong partisipasi (Defranesco et al., 2008). Berdasarkan penelitian lapang, jenjang pendidikan formal petani terdiri dari pendidikan sekolah dasar, sekolah menengah pertama, sekolah menengah atas serta perguruan tinggi.

Tabel 1. Faktor Pendidikan Formal Mempengaruhi Partisipasi

\begin{tabular}{llr}
\hline \hline $\begin{array}{l}\text { Faktor yang } \\
\text { Mempengaruhi }\end{array}$ & $\begin{array}{l}\text { Pengaruhnya } \\
\text { terhadap Partisipasi }\end{array}$ \\
\hline Pendidikan & $\bullet$ Sebagian & besar \\
Formal & $\begin{array}{l}\text { petani } \\
\text { mengikuti }\end{array}$ & yang \\
& berpendiatan \\
& & \\
& Petani & dengan \\
& jenjang pendidikan \\
& yang & masih \\
& tergolong rendah / \\
& SD, secara umum \\
& sulit untuk melihat \\
& perubahan ran ke \\
& depannya sehingga \\
& sulit juga untuk bisa \\
& diajak berkembang \\
\hline \hline
\end{tabular}

Tingkat pendidikan formal petani Kelompok Tani Bahagia IV mempengaruhi keputusan petani di dalam mengikuti kegiatan pengolahan pupuk organik. Petani dengan 
pendidikan yang hanya setara SD atau

SMP dibandingkan dengan petani yang menempuh pendidikan SMA, secara umum kurang bisa diajak untuk berkembang dan bekerja sama dalam kegiatan. Partisipasi petani dalam kegiatan pengolahan pupuk organik lebih banyak diikuti oleh petani yang telah menempuh pendidikan SMA. Slamet (1993) mengemukakan bahwa semakin tinggi tingkat pendidikan seseorang, semakin tinggi pula dalam berpartisipasi dan berpendapat.

b. Pendidikan nonformal

Kegiatan pengolahan pupuk organik diawali dengan adanya pelatihan pengolahan pupuk organik. Dari berbagai pelatihan yang diadakan baik oleh dinas pertanian maupun pengurus kelompok tani tersebut, petani mendapatkan pengetahuan mengenai pupuk organik, seperti bahan yang mudah didapatkan, proses pembuatan sampai manfaat yang didapatkan petani. Lebih lanjut, petani kemudian melaksanakan pertemuan serta rapat kelompok yang didalamnya melakukan musyawarah membahas kegiatan kelompok. termasuk menjadikan pengolahan pupuk kompos menjadi kegiatan kelompok.

Pendidikan nonformal yang diikuti petani digolongkan mampu mempengaruhi keputusan petani untuk berpartisipasi di dalam kegiatan pengolahan pupuk organik. Pendidikan nonformal yang dimaksud disini berupa pelatihan dan pertemuan yang membahas pupuk organik. Semakin banyak kegiatan nonformal yang diikuti petani ikut mendorong perkembangan pola berpikir petani serta memudahkan petani untuk menerima informasi dan inovasi, sehingga petani lebih terdorong untuk berpartisipasi dalam kegiatan pengolahan pupuk organik. Pendidikan nonformal oleh Prijono et al. (1996) sebagai program sosialisasi jenis keterampilan kerja praktis yang sesuai kebutuhan masyarakat. Hasil penelitian Anggini et al. (2019) menunjukkan bahwa dalam pemanfaatan limbah sayuran sebagai pupuk bokashi, kegiatan penyuluhan berpengaruh positif terhadap perilaku petani. Semakin tinggi intensitas kegiatan penyuluhan, berikut materi, media dan metode penyuluhan yang sesuai dengan kebutuhan petani, maka semakin antusias perilaku petani dalam memanfaatkan pupuk bokashi.

\section{Pekerjaan}

Kebutuhan petani pada pupuk organik untuk digunakan pada lahan mereka, termasuk faktor yang mendorong petani untuk berpartisipasi dalam kegiatan pengolahan pupuk organik. Di sisi lain, pada sebagian besar petani belum cukup apabila hanya mengandalkan penghasilan dari bertani untuk kebutuhan sehari-hari mereka. Akibatnya, petani memiliki lebih dari satu pekerjaan. Pekerjaan lain yang diusahakan petani mempengaruhi partisipasi petani dalam kegiatan 
dikarenakan fokus pikiran dan waktu petani terbagi. Petani umumnya lebih memilih bekerja di bidang pekerjaan lain seperti menjadi kuli bangunan, kuli angkut bawang (nyonggol), berdagang, peternak maupun memancing ikan untuk dijual; untuk menambah penghasilan, menyebabkan petani tidak memiliki cukup waktu untuk mengikuti kegiatan pengolahan pupuk organik. Sesuai dengan Ife dan Tesoriero (2008) yang menyatakan bahwa meningkatnya permintaan akan pekerjaan, membuat mereka yang bekerja menemukan kekurangan waktu dan energi untuk berpartisipasi dalam masyarakat. Tingkat partisipasi menurut Hasyim (2006) dipengaruhi oleh berbagai faktor yang berasal dari masyarakat itu sendiri.

\section{Akses Komunikasi}

\section{Akses}

komunikasi

mempengaruhi keikutsertaan petani dalam kegiatan. Sumber informasi yang paling dipercaya petani yaitu informasi yang disampaikan oleh Penyuluh Pertanian Lapang (PPL) atau pegawai terkait dari Dinas Pertanian Brebes. Hal tersebut karena PPL atau pegawai dari Dinas Pertanian Brebes, oleh petani dirasa memiliki pengetahuan yang lebih luas dibandingkan dengan petani sendiri. Setiawan (2015) menyatakan bahwa penyuluh dapat membantu terkait penyediaan informasi dan memberikan pandangan mengenai masalah yang dibutuhkan petani. Grovermann et al. dalam Wuepper et al. (2020) menambahkan bahwa ketika melakukan pembahasan mengenai pestisida, penyuluh pertanian sebagai sumber informasi bagi petani, lebih menyoroti pada dampak buruk pestisida terhadap lingkungan, kemungkinan resiko pestisida bagi kesehatan konsumen dan petani; serta peningkatan resistensi pestisida, serta melakukan rekomendasi strategi yang dapat digunakan untuk mengurangi penggunaan pestisida.

Terkait dengan kemudahan mengakses informasi kegiatan pengolahan pupuk organik, petani dapat mengakses informasi dengan cukup mudah dengan berbicara dengan sesama petani di keseharian maupun bertanya saat adanya pertemuan.Ketersediaan informasi juga sudah cukup banyak dan mudah didapatkan petani. Berkaitan dengan indikator manfaat, kebutuhan petani akan pupuk organik dapat dipenuhi dengan ikut memanfaatkan produk pupuk organik yang dihasilkan kelompok.

\section{KESIMPULAN DAN SARAN}

Kegiatan pengolahan pupuk organik merupakan kegiatan kelompok yang dilaksanakan secara mandiri oleh Kelompok Tani Bahagia IV, Desa Banjaratma, Kecamatan Bulakamba, Kabupaten Brebes. Kekhawatiran dan kesadaran akan penggunaan pupuk kimia berlebih yang mengakibatkan produktivitas lahan menurun, mendorong petani untuk mengembangkan dan memproduksi pupuk 
organik sebagai kegiatan kelompok, dengan hasil produk yang dikomersialkan ke petanipetani sekitar. Pada pelaksanaannya, berbagai faktor yang mempengaruhi partisipasi petani Kelompok Tani Bahagia IV dalam kegiatan pengolahan pupuk organik meliputi umur, pendidikan formal dan atau nonformal petani, pekerjaan dan akses komunikasi.

Petani Kelompok Tani Bahagia IV diharapkan dapat berpartisipasi secara aktif dalam setiap tahap kegiatan pengolahan pupuk organik karena keikutsertaan petani berpengaruh terhadap keberlangsungan dan keberlanjutan kegiatan pengolahan pupuk organik. Kelompok Tani Bahagia IV diharapkan membuat penjadwalan kegiatan bagi petani dalam proses produksi, sehingga setiap individu petani memiliki peran dan tanggung jawab yang sama atas keberlangsungan kegiatan. Optimalisasi peran serta petani dalam pengolahan pupuk organik sebagai kegiatan usaha kelompok perlu direalisasikan, agar dapat bekembang menjadi usaha kelompok yang lebih baik.

\section{DAFTAR PUSTAKA}

[Bappenas] Badan Perencanaan Pembangunan Nasional. (2001). Majalah Perencanaan Pembangunan Edisi 23. https://www.bappenas.go.id/id/datadan-informasi-utama/makalah/artikelmajalah-perencanaan/edisi-23-tahun2001/

[UU RI] Undang-Undang Republik Indonesia. (2003). Undang-undang Republik Indonesia Nomor 20 tahun 2003 tentang Sistem Pendidikan. Nasional. https://peraturan.go.id/common/doku men/ln/2003/uu20-2003.pdf

Anggini, D., Hartono, R., \& Anwarudin, O. (2019). Perilaku petani dalam pemanfaatan limbah sayuran sebagai pupuk bokashi pada tanaman sawi putih. Jurnal Triton, 10(1), 99-115.

Bahar, Y. (2016). Dampak perilaku petani dalam budidaya bawang merah terhadap perubahan kondisi agroekosistem di Kabupaten Brebes. Jurnal Penyuluhan Pertanian, 11(1), 23-36.

Bhinadi, A (2017). Penanggulangan Kemiskinan dan Pemberdayaan Masyarakat. Yogyakarta: Deepublish.

Defrancesco, E., Paola, F., \& Samuele. (2008). Factors affecting farmers' participation in agri-enviromental measures: A Nothern Italian Perspective. Journal of Agriculture Economics, 59(1), 114131.

Faisal, S. (1992). Format-Format Penelitian Sosial. Jakarta: Rajawali Press.

Hardjowigeno, S. (2007). Ilmu Tanah. Jakarta: Akademika Pressindo.

Hasyim, H. (2006). Analisis hubungan karakteristik petani kopi terhadap pendapatan (studi kasus: Desa Dolok Seribu Kecamatan Paguran Kabupaten Tapanuli Utara). J. Komunikasi Penelitian Lembaga Penelitian. Universitas Sumatera Utara, Medan

Ife, J., \& Tesoriero, F. (2008). Alternatif Pengembangan Masyarakat di Era Globalisasi: Community Development. Yogyakarta: Pustaka Pelajar.

Mardikanto. (2013). Pemberdayaan Masyarakat dalam Perpsektif Kebijakan Publik. Surakarta: UNS Press.

Moeloeng, L. (2000). Metodologi Penelitian Kualitatif. Bandung: Remaja Posdakarya.

Munfati, N. (2017). Partisipasi petani dalam program seribu hektar sistem tanam padi jajar legowo di Kecamatan Karangpandan, Kabupaten Karanganyar. Jurnal Agritex, 41(1), 43-54. 
Pan, D. (2014). The impact of agricultural extension on farmer nutrient management behaviour in chinese rice production: a household-level analysis. Sustainability, 6, 6644-6665.

Prijono, O.S. \& Pranarka, A.M.W. (1996). Pemberdayaan: Konsep, Kebijakan dan Implementasi. Jakarta: Centre For Strategic and International Studies (CSIS).

Putri, C.A., Anwarudin, O., \& Dwiwanti, S. (2019). Partisipasi petani dalam kegiatan penyuluhan dan adopsi pemupukan padi sawah di Kecamatan Kersamanah Kabupaten Garut. Jurnal Agribisnis Terpadu, 12(1), 103-119.

Setyorini, D., Rochayati, \& Las. (2010). Pertanian Pada Ekosistem Lahan Sawah. Badan Penelitian dan Pengembangan Pertanian Kementerian Pertanian. Bogor: IPB Press.

Setiawan, A. (2015). Kajian analitik masalahmasalah penyuluhan pertanian. Jurnal Penyuluhan, 1(1), 57-61.

Slamet, M. (1993). Pembangunan Masyarakat Berwawasan Partisipasi. Surakarta: UNS Press.

Soekarwati. (2005). Prinsip Dasar Ekonomi Pertanian. Jakarta: Raja Grafindo Persada

Sugiyono. (2009). Metode Penelitian Kuantitatif Kualitatif dan R\&D. Bandung: Alfabeta.

Sumarno. (2012). Konsep Pelestarian Sumber Daya Lahan Pertanian dan Kebutuhan Teknologi. Iptek Tanaman Pangan, 7(2), 130-141.

Suradisastra, K., Pasaribu, Sayaka, B., Dariah, A., Las, I., \& Haryono, P. (2010). Membalik Kecenderungan Degradasi Sumber Daya Lahan dan Air. Bogor: IPB Press.

Wuepper, D., Nikolaus R., \& Robert F. (2020). Does it matter who advices farmers? Pest management choices with public and private extension.
J. Foodpol, 101995, 1-8. DOI:10.1016/j.foodpol.2020.101995.

Yanto, M \& Eni. (2003). Motivasi petani samin dalam menanam kacang tanah (studi kasus di Dukuh Tandura Desa Kemantren Kecamatan Kedungtuban Kabupaten Blora). Agritexts, 14, 23-32. 